\title{
A representação do vestuário da elite feminina carioca (1854-1864) em Diva, de José de Alencar
}

\author{
The representation of the clothing of the elite women of Rio de Janeiro in Diva \\ (1854-1864), by José de Alencar
}

\author{
Fernanda de Oliveira Conceição* \\ Universidade Estadual de Feira de Santana \\ Feira de Santana, Bahia, Brasil \\ Adeítalo Manoel Pinho** \\ Universidade Estadual de Feira de Santana \\ Feira de Santana, Bahia, Brasil
}

\begin{abstract}
Resumo: O objetivo deste artigo foi entender como José de Alencar (1829-1877) representou o vestuário da elite feminina carioca (1854-1864) na diegese de seu romance urbano Diva (1959 [1864]). É de interesse não apenas à esfera acadêmica, cuja necessidade está em atualizar a obra alencariana, tendo aparo em aportes teóricos que possibilitem elucidar sua complexidade, provocando, com isso, outro olhar do século XIX, que se reflete na contemporaneidade; mas também aos estudos de gênero, permitindo entrever, por meio do vestuário, a atuação social da mulher de elite no período correspondente ao recorte temporal (1854-1864) e refletir sobre como o papel que lhe foi designado permanece hoje - desta vez, seu alcance não se limitando a apenas uma classe social. Como referencial teórico, há contribuições de Genette (2017 [1972]) e Sant'anna (1979 [1973]) à Narratologia e fizemos cotejo entre a pesquisa e outros trabalhos que mantêm relação com o tópico, como os de Hernandes (2015), Lajolo; Zilberman (1996), Souza (1993, 2005), dentre outros. Envolvido nos assuntos de seu tempo, Alencar acertou sobre os temas que escolheu escrever, garantindo às obras uma possível recepção por parte do público-alvo, seja através de leitoras fictícias que elaborou para garantir tal aceitação, seja na representação da vida privada do homem comum.
\end{abstract}

Palavras-chave: Diva. José de Alencar. Diegese. Vestuário.

\begin{abstract}
The aim of this paper was to understand how José de Alencar (1829-1877) represented the clothing of the elite women of Rio de Janeiro (1854-1864) in the diegesis of his urban novel Diva (1959 [1864]). It is of interest not only to the academic area, which need is to update the work of Alencar, based on theoretical contributions that can elucidate its complexity, causing, with this, another view of the nineteenth century, which is reflected in contemporaneity; but also to gender studies, allowing to visualize, through clothing, the social performance of the elite women in the period corresponding to the temporal cut (1854-1864) and to reflect on how the role assigned to them remains today - this time, its reach is not limited to just one social class. As a theoretical framework, there are contributions of Genette (2017 [1972]) and Sant'anna (1979 [1973]) to Narratology and we compared the research with other
\end{abstract}

\footnotetext{
* Graduada em Letras com Inglês pela Universidade Estadual de Feira de Santana - UEFS. Participa do Grupo de Estudos Literários Contemporâneos - GELC, do Programa de Pós-Graduação em Estudos Literários - PROGEL, da UEFS. E-mail: nanda.letrasuefs@gmail.com.

** Professor titular de Literatura Brasileira, do Departamento de Letras e Artes, da UEFS. Coordenador do GELC (PROGEL/UEFS). Doutor em Linguística e Letras pela Pontifícia Universidade Católica do Rio Grande do Sul. Mestre em Letras e Linguística pela Universidade Federal da Bahia. E-mail: adeitalopinho@gmail.com.
} 
works related to the topic, such as the works of Hernandes (2015), Lajolo; Zilberman (1996), Souza (1993, 2005), among others. Involved in issues of his time, Alencar was right about the themes he chose to write, guaranteeing the works a possible reception by the target audience, either through fictitious readers he designed to guarantee such acceptance, or in his representation of the private life of the common man.

Keywords: Diva. José de Alencar. Diegesis. Clothing.

\section{INTRODUÇÃO}

José Martiniano de Alencar (1829-1877) - eternizado em nossa literatura como José de Alencar - possuiu muitas ocupações durante o curto tempo em que viveu: foi romancista (um dos principais representantes do movimento romântico no Brasil), poeta, cronista, dramaturgo, teatrólogo, advogado, ministro da justiça e, até mesmo, desafeto do imperador D. Pedro II (1825-1891). Tudo isso permite hoje considerá-lo "[...] um indivíduo de visão progressista [...], [pois] tinha consciência de seu papel enquanto homem das letras do seu tempo e não duvidava de que a literatura refletisse a alma da nação, contribuindo para a formação de sua identidade" (SILVA, 2011, p. 81).

Foi aquela nação recém-independente chamada Brasil, que ainda não se reconhecia como tal, que teve em vista o seu projeto nacionalista, visando formar e consolidar a identidade brasileira. Aí, através das letras, Alencar designou como herói brasileiro o índio; adotou o gênero romance, ajudando a prosa brasileira a se distanciar da literatura clássica portuguesa à moda dos versos camonianos; e defendeu a inovação da língua portuguesa, para que fosse possível, de acordo com Mendes (1965), apresentar tanto da época colonial, quanto do Segundo Reinado, da corte, ou das regiões geográficas mais distantes,

[...] cenários, ambientes, personagens, modas, costumes, linguagem, ideais políticos e sociais, um mundo de gente viva e atuante, mural colorido, sentimental, romântico e realista ao mesmo tempo, da vida brasileira. Da vida brasileira e só da vida brasileira, porque Alencar foi um escritor essencial, intensa e profundamente brasileiro. (MENDES, 1965, p. 9).

Situou-se entre os anos de 1851 a 1863 a efervescência do reinado de D. Pedro II, no sentido das diversas transformações que o Brasil sofreu econômica e socialmente, das inovações tecnológicas que surgiram e da vida citadina que começava a se desenvolver, com o apogeu dos salões e teatros. É nesse período que Alencar entra para a política e escreve alguns de seus romances urbanos, como Diva (1959 [1864] $)^{1}$, ambientado na cidade do Rio de Janeiro, além de muitas peças de teatro.

\footnotetext{
${ }^{1}$ Sua primeira publicação data de 1864, pela Editora Garnier. Usaremos para análise dos romances de Alencar aqui citados o volume I (Romances Urbanos), da edição de 1959, lançada pela Editora José Aguilar, que traz a obra completa do autor em quatro volumes.
} 
O casamento, instituição por excelência daquela sociedade a que estão inseridos os personagens de Diva, é configurado de acordo com conveniências, dotes polpudos e - por que não? - o quanto de elegância uma moça fosse capaz de exibir no modo de se vestir e se comportar. É Augusto Amaral que confessa à Emília Duarte:

- À exceção do comércio, a senhora sabe que não há no Brasil carreira alguma pela qual se possa chegar depressa... e honestamente, à riqueza. A minha [médico], mal dá para viver com decência. Portanto sendo eu honesto [...], só havia um recurso à minha ambição... Advinha qual? [...] o do casamento 2. (ALENCAR, 1959 [1864], p. 554).

De tal modo, o matrimônio nem sempre se constituiu resultado do encontro de duas almas gêmeas. O amor foi uma invenção da burguesia inglesa do século XVIII - no Brasil, os casais vieram a se unir por consentimento próprio apenas no fim do século XIX -, que teve como fim garantir herdeiros legítimos quando os casamentos consanguíneos da aristocracia deixaram de existir, após o surgimento do capitalismo. Ao refletir o caráter individualista deste, o amor recíproco, monogâmico, possessivo tornou-se o pilar do novo sistema econômico. Portanto, foi na Inglaterra, pioneira também na Revolução Industrial, que, ainda nos setecentos, “[...] a família patriarcal [passou a constituir] um empecilho para o individualismo, e talvez tenha sido por essa razão que o sistema da família conjugal se impôs mais nas sociedades individualistas e protestantes, sendo, na essência, urbano e típico da classe média" (WATT, 1990, p. 124).

O Brasil, recém-independente de Portugal, ainda era, em meados do século XIX, uma sociedade fortemente rural e patriarcal, que promovia casamentos de conveniência para garantir a sobrevivência de suas fazendas de café. É possível que tal atraso configurou-se como empecilho aos nossos românticos para concretizarem o amor sentimental que aprenderam em versos como os de Lord Byron (1788-1824) e John Keats (1795-1821). Às mulheres da elite, casar era uma preocupação constante. Desde cedo aprendendo a "arte de ser mulher", ao educarem-se na música e no francês, na dança e na culinária, deveriam, por conseguinte, conquistar um bom pretendente, com suas prendas, bom comportamento e um generoso dote a oferecer. Nos bailes de que frequentavam, seguiam um rigoroso protocolo no "jogo de aceite e recusa", reminiscência, em pleno Brasil dos oitocentos, do amor cortês, que preencheu a corte do Segundo Reinado com "[...] um sortilégio de olhares embebidos de paixão, gestos sedutores, recusas, sofrimentos, [...], enfim - traços que compunham a arte de amar medieval [...]" (CONCEIÇÃO); ARAÚJO, 2016, p. 372). Após a abertura dos portos por D. João VI (1767-1826) e a criação da Impressão Régia em 1808, as tipografias alastraram-se por todo o século XIX, publicando periódicos sobre todos os assuntos. $\mathrm{O}$ acesso, mesmo que limitado à leitura, chegou à elite feminina na forma de romances-folhetins e de revistas voltadas a esse público.

\footnotetext{
2 Manteremos, a partir daqui, a grafia original do texto em todas as ocorrências em que se faz
} necessário. 
Com o crescente estabelecimento de livreiros franceses e gabinetes de leitura, o acesso aos romances ingleses e franceses também se fez possível. A educação da mulher era monitorada por perto pelos homens de sua família. Era necessário que fosse bem instruída, para instruir igualmente bem os seus filhos e ser uma fonte caseira de sabedoria e bons conselhos para seu marido. E mesmo aquelas à margem, que tiveram acesso a uma instrução mais avançada, não o foi para ganharem um novo papel, "mas simplesmente [...] trazer novos padrões para regular a convivência da mulher em sociedade, de tal modo que não fosse ameaçado o seu destino natural de mãe e esposa dos homens ilustrados" (REIS, 2000, p. 243).

Logo, a escrita e a leitura pelas mulheres, principalmente dos romancesfolhetins, eram uma distração perigosa, capazes de lhes inculcar ideias perniciosas. Por tal motivo, era encorajada a leitura em voz alta. E para que os romances fossem aceitos, suas personagens deveriam servir como espelhos às moças: ora possuindo boa conduta e exemplo a seguir, ora alertando-as para as consequências que atitudes desregradas sofreriam. À vista disso, “junta-se assim a capacitação para a leitura às demais habilitações requeridas pela educação feminina. No conjunto, reforçavam todas o lugar social da mulher: sua educação, por melhor que fosse, dirigia-a à ocupação deste papel, ao cumprimento das tarefas de esposa e mãe" (LAJOLO; ZILBERMAN, 1996, p. 257). As revistas direcionadas ao público feminino continham receitas, descrições de lugares, seções de literatura, lições de comportamento e, principalmente, instruções de como se vestir de acordo com as últimas tendências de Paris, centro da moda europeia na época.

\section{A ANÁLISE DO DISCURSO NARRATIVO DE GÉRARD GENETTE}

Segundo Genette ${ }^{3}$ (2017 [1972], p. 83), a narrativa é resultado de uma ação, do ato de narrar. Tudo começa pela instância narrativa: um acontecimento real ou ficcional; uma carta recebida; uma fotografia que tirou num passeio; os registros, os mais íntimos na maioria das vezes, contidos nas páginas do diário que o narrador tem ou sente necessidade de contar sobre. E a maneira pela qual informa a outrem sobre isso contém um estilo próprio, ou corresponde ao de uma época. A esse estilo, a essa maneira chamou Genette (2017 [1972], p. 85) de "narrativa" ou "discurso narrativo". Até mesmo o silêncio pode ser uma instância narrativa, e o discurso que o informa o capta de imediato, sendo por isso de profundidade alógica, um "fluxo de consciência", como ficou conhecido o estilo de Virginia Woolf (1882-1941), Clarice Lispector (1920-1977) e James Joyce (1882-1941), por exemplo.

A narrativa sob essa perspectiva tem a função de contar uma história, ou diegese. Para o teórico francês, não deve então existir a oposição platônica entre a narrativa mimética emprestada do teatro e a narrativa pura, ou, "diegesis": "[do ato narrativo] dependem não somente a existência do discurso [narrativo] [sic] mas a ficção de existência das ações que ele 'reporta"' (GENETTE, 2017 [1972], p. 84).

3 Gérard Genette (1930-2018), teórico literário francês. Foi professor de literatura francesa na Sorbonne. 
Em seu discurso narrativo, um autor decide como e sob qual ponto de vista irá informar ao seu leitor sobre o que quer que seja, incorrendo em maior ou menor distância (graus de mimésis, ou modalidades de representação) da instância narrativa (narração). São esses graus que aproximam ou distanciam um romance fictício como foi Diva, por exemplo, do ponto de vista do que seja a realidade para a ideologia que Alencar reproduziu. Conforme Genette (2017 [1972], p. 87), a análise do discurso narrativo, portanto, é um estudo das relações entre três categorias: as relações temporais entre narrativa e diegese - TEMPO; as modalidades (formas e graus) da representação narrativa - MODOS; e como se acha implicada na narrativa a própria narração - VOZ. Se a narrativa antecipa um acontecimento ou faz uma retrospecção deste no tempo; se é uma narrativa de falas - conhecida como discurso direto, em "primeira pessoa" -, ou uma narrativa de acontecimentos - conhecida, por sua vez, como discurso indireto, em "terceira pessoa" - em seu modo como transmite a informação narrativa; ou ainda, se a voz que nos fala se localiza ou não no nível da diegese e a relação que mantém com esta, além do público a que se dirige (o narratário): aqui temos os graus de mimésis, que se relacionam entre si, montando o discurso.

Genette aplicou este ensaio de método à obra de Marcel Proust (1871-1922), Em busca do tempo perdido (entre 1913 e 1927), por isso há muitas particularidades concernentes ao discurso proustiano. Para ser aplicada à obra de Alencar, tal teoria precisou ser adaptada por nós, e alguns conceitos mesmo, revistos. Como a definição de metadiegese, que para Genette (2017 [1972], p. 309) diz respeito a uma narrativa segunda, que mantém uma relação direta, indireta ou, até mesmo, sem nenhuma importância entre seus acontecimentos e os da narrativa primeira, a diegese. É o "eis por que" balzaquiano, a título de curiosidade do narratário em saber o que motivou tais acontecimentos na história. Constitui-se como o referencial histórico da diegese que, no Em busca do tempo perdido, localiza-se em um de seus volumes, reservado especificamente para tal fim. Em Diva, também consideramos como metadiegese o referencial histórico de sua diegese; contudo, ao contrário de Genette, que evita confundir "[...] o ato de Marcel contando sua vida passada [...] com o ato de Proust escrevendo Em busca do tempo perdido [...]" (GENETTE, 2017 [1972], p. 86), localizamos tal referencial fora do nível narrativo, na História, mais precisamente, na história pessoal de José de Alencar, como deixaremos detalhado a seguir.

\section{FIGURINOS FEMININOS EM PERIÓDICOS CARIOCAS DO SÉCULO XIX}

Dentre os romances urbanos de José de Alencar, decidimo-nos por Diva, pois aqui o vestuário, em relação à Lucíla (1959 [1862]), por exemplo, foi transposto para a diegese da obra quase certamente com o propósito de atrair a atenção da leitora, para que esta se identificasse com aquele; em segundo lugar, esse perfil, em comparação aos outros, é ainda objeto de poucas discussões nas academias, sendo, portanto, um romance com muitas interpretações a serem exploradas. 
Quanto às revistas femininas, foram três: a primeira delas é o Jornal das senhoras: moda, litteratura, bellas-artes e theatros, que circulou semanalmente na cidade do Rio de Janeiro, entre 1852 e 1855. Redigida pela argentina Joana Paula Manso de Noronha, foi o primeiro periódico elaborado por mulheres e para mulheres. Continha seções, como o título já diz, de peças de teatro em exposição, artigos de moda e publicações dos chamados romances-folhetins - "é preciso lembrar de que são as histórias publicadas em capítulos as primeiras a arregimentar algum dinheiro e fôlego à imprensa brasileira" (PINHO, A., 2009, p. 116). A segunda é O espelho: revista semanal de litteratura, modas, industria e artes, também carioca, que foi editado sob a responsabilidade de F. Eleuterio de Souza, e sua equipe de colaboradores contou com nomes como Machado de Assis e Casimiro de Abreu (1839-1860). De circulação dominical, durou apenas seis meses, entre os anos de 1859 e 1860. Continha artigos sobre modas, teatro, romances, poesias, enfim, tudo o mais que fosse de interesse do "bello sexo". Finalmente, A primavera: revista semanal de litteratura, modas, industria e artes, sendo sua primeira edição datada de 03 de março de 1861, sob a responsabilidade de Azeredo Leite. Localizada no n. 9 da Rua do Ouvidor, também contou com contribuições de Machado de Assis. Era de circulação semanal, mas não há informações de sua duração, sendo sua primeira edição a única disponível na Hemeroteca Digital Brasileira.

Para selecioná-las, levamos em conta, em primeiro lugar, sua disponibilidade online no portal Hemeroteca Digital Brasileira, da Fundação Biblioteca Nacional ${ }^{4}$; em segundo lugar, sua produção, que deveria estar voltada para o público feminino; em terceiro lugar, sua redação de responsabilidade tanto de homens, quanto de mulheres; em quarto e último lugar, a presença de descrições detalhadas de figurinos.

Quanto à definição do recorte temporal, tomamos por referência, no nível metadiegético, o período de namoro entre José de Alencar e a Viscondessa Francisca Nogueira da Gama. A metadiegese é o universo da narrativa segunda, ou diegese. É possível haver uma causalidade direta, de acordo com Genette (2017 [1972], p. 310), entre os acontecimentos da diegese e da metadiegese, que confere a esta uma função explicativa. Responsável pela instância narrativa (narração) da metadiegese, Alencar é o autor real de Diva, enquanto Augusto Amaral, responsável pela instância narrativa extradiegética, é seu autor fictício. O referente histórico da narração de Alencar, que transpõe detalhes para a narração de Augusto, é o seu namoro com a Viscondessa. Esta informação se encontra nos registros históricos: segundo Pinho, W. ([19--?], p. 158), Alencar cortejou incessantemente a moça, que conheceu no Cassino e em reuniões na casa do Cons. Nabuco Araújo, ou de Diogo Velho. Ela, porém, nunca o correspondeu, e sua indiferença teria inspirado as páginas de Diva e Senhora (1859 [1875]). Provavelmente, conhecera-a em setembro de 1854, pois data dessa época uma crônica de sua autoria, em que descreve uma mulher, cujo rosto iluminava-se com um sorriso, valsando modestamente na companhia de outro homem. A Viscondessa "partiu com os pais em 17 de março de 1855 para uma longa viagem pela Europa, [e] Alencar, em crônica datada do dia seguinte, escrevia: 'tudo parte,

${ }^{4}$ Cf. em: http://bndigital.bn.gov.br/hemeroteca-digital/. 
tudo vai mar em fora, ver novos climas, correr terras para ter na volta o que contar"” (PINHO, W., [19--?], p. 159). Ela casou-se em 1862 com o Visconde de Penamacor. Diva, “[...] o segundo 'perfil de mulher', apareceu em 1864” (MENDES, 1965, p. 36), e foi escrito "antes do fim do ano [de 1863]" (FILHO, 1979, p. 119), um ano após o casamento dela. Portanto, pode ser que "'Diva' afigura um livro de intenção, escrito para uma antiga namorada, descrita para ser humilhada num final de entrecho em que a adoidada e caprichosa se vê vencida e subjugada pelo amor que lhe despertara aquêle mesmo que tantas vêzes molestara" (PINHO, W., [19--?], p. 162).

A atitude de uma senhora para com seus admiradores certa vez no Cassino, descrita em uma crônica datada de 13 de maio de 1855 e publicada no Correio mercantil como "[...] uma bela roseira, coberta de flôres, em tôrno da qual os colibris adejavam a ver se colhiam um sorriso ou uma palavra meiga e terna, [mas que] só tinha espinhos para os que se chegavam a ela [...]" (ALENCAR, [19--], p. 187), pode também ter servido (não há confirmação) de inspiração para o comportamento de Emília quando, ainda não acostumada aos bailes, “[...] algum mais apaixonado ou menos perspicaz de seus admiradores ousava transpor aquela régia altivez e casta auréola em que ela resplandecia, então sua cólera revestia certa majestade olímpia que fulminava" (ALENCAR, 1959 [1864], p. 480).

No nível diegético, referimo-nos à noção de dualidade entre o tempo da coisacontada ou da história e o tempo da narrativa, designações de Genette (2017 [1972], p. 91) para o tempo do significado e o tempo do significante, respectivamente. A reconstituição do tempo da história só será possível, ainda conforme Genette (2017 [1972], p. 90), se confrontada sua relação com o (pseudo) tempo da narrativa, segundo três determinações: a ordem, a duração e a frequência. Aqui nos limitamos à primeira, e algumas informações sobre datas só serão reveladas quando confrontada a "[...] ordem da disposição dos acontecimentos ou segmentos temporais no discurso narrativo com a ordem de sucessão desses mesmos acontecimentos ou segmentos temporais na história [...]" (GENETTE, 2017 [1972], p. 93). A narrativa de Paulo, protagonista de Luciola e leitor (narratário virtual de Augusto), informa numa espécie de prólogo a G.M., leitora fictícia de Alencar e aqui, editora de Diva, a data da sua viagem à Europa com duração de dois anos, em que conhecera o Dr. Augusto Amaral: março de 1856. Caracterizamos essa narrativa segunda, subordinada à narrativa primeira, como uma prolepse interna heterodiegética, que evoca por antecipação e mais detalhadamente um segmento temporal que na diegese faz uma retrospectiva sua, sob a forma de narração sumária, caracterizando-se, por sua vez, como uma analepse interna heterodiegética. Por este indício, pudemos inferir certas informações: Augusto, o narrador-autor (personagem em sua própria narrativa) de Diva, informa a Paulo, seu leitor (narratário virtual), que conhecera Emília Duarte, a protagonista do romance, com catorze anos. Consideramos então que tenha sido em setembro de 1855, segmento temporal disposto em duas páginas na narrativa (1959 [1864], p. 463-464). Dois meses depois, em dezembro, "no verão de 1855" (ALENCAR, 1959 [1864], p. 465), tratou de uma enfermidade grave que acometia Emília. Três meses depois (em março), o Dr. Amaral vai à Europa especializar-se, 
retornando dois anos depois, hipoteticamente em março de 1858. Emília constava, então, dezessete anos. Ele admira seu amadurecimento até os dezoito. Desta forma, há uma correspondência entre o tempo diegético e o metadiegético, tendo o relacionamento entre Emília e Augusto, e a Viscondessa e Alencar, durado, aproximadamente, três anos. Relacionando a diegese e a metadiegese, tem-se um período arrolado entre 1854 e 1863. Consideramos ainda o ano de publicação de Diva, 1864. Portanto, o recorte temporal situa-se entre 1854 e 1864.

As variantes que compõem o problema de pesquisa são "representação" e "vestuário". Tomamos, como conceito da primeira, a definição de Genette (2017 [1972]):

pode-se de fato narrar mais ou menos o que se narra, e narrá-lo segundo tal ou qual ponto de vista; é precisamente essa capacidade, e as modalidades de seu exercício que visa nossa categoria de modo narrativo: a "representação", ou mais exatamente, a informação narrativa tem seus graus; a narrativa pode fornecer ao leitor mais ou menos detalhes, e de forma mais ou menos direta, e parecer assim [...] se situar numa maior ou menor distância daquilo que se narra [...]. (GENETTE, 2017 [1972], p. 232-233, grifo do autor).

Quanto à variante "vestuário", este foi considerado um elemento pertencente à metadiegese e transposto à diegese. Complementa a indumentária da elite feminina os tipos de penteado, calçados e acessórios (chapéu, luvas, ramo de flores etc). Aqui, foram considerados como indicadores os vestidos e dos acessórios, apenas as luvas. Quanto ao conceito de representação, este foi mensurado na pesquisa pelo seguinte indicador: os graus de distância (com mais ou menos detalhes, de forma mais ou menos direta) que possui a informação narrativa (caracterização do vestuário da elite feminina carioca) dada por Alencar. Logo, como se deu a sua representação do vestuário da elite feminina carioca, que é o problema desta pesquisa, dependeu dos graus de distância que a sua informação narrativa manteve com as características do vestuário de 1854-1864 presentes nas revistas e transpostas para a diegese da obra Diva.

A partir disto, foram utilizadas as edições de número 2, 6, 11 e 24, do ano de 1855, do Jornal das senhoras: moda, litteratura, bellas-artes e theatros; as de número 1 e 2, de 1859, d'O espelho: revista semanal de litteratura, modas, industria e artes; e a edição de número 2 , de 1861 , d'A primavera: revista semanal de litteratura, modas, industria e artes. A análise qualitativa do romance, sobre o qual foram estabelecidas descrições dos vestuários, foi norteada por três pontos, que compuseram a ficha de análise do texto literário: 1. Selecionar no romance Diva todas as passagens que descrevem o vestuário; 2. Buscar, nas revistas femininas, descrições do vestuário da elite feminina carioca que informem quanto à sua forma, cor, tecido e regras de uso (vestido para baile, passeio, estar em casa etc); 3. Observar em que e de quais maneiras as descrições do primeiro e segundo pontos se assemelham e se diferem entre si.

\section{UMA TEORIA DAS NARRATIVAS BRASILEIRAS}


Realizar um trabalho analítico que decompusesse a estrutura dos romances brasileiros, a partir da teoria da linguagem de Ferdinand de Saussure (1857-1913): é o que tinha em mente o professor Affonso Romano de Sant'anna ${ }^{5}$, ao publicar o seu livro Análise estrutural de romances brasileiros (1973). Recebeu inúmeras críticas, e uma em que o professor Antonio Candido ${ }^{6}$ (1918-2017) discorda de sua análise d'O cortiço (1890), de Aluísio Azevedo (1857-1913). Mas o fato é que, por mais estrutural que seja seu modo de ler os romances brasileiros, tanto os do século XIX quanto os da contemporaneidade, Sant'anna não procurou tomar partido a favor de uma corrente, de um movimento ou de um credo. Situando-se acima da categorização didática e minimalista conhecida como série literária, Sant’anna (1979 [1973], p. 18-19) apresenta dois modelos interpretativos de narrativa: um, "a narrativa de estrutura simples", de tradição oral, ligada ao mítico e ao ideológico e que, por isso, reproduz e reafirma a ideologia da estética à que está ligada. Este modelo denota, desta forma, um significado explícito, já que, "assim como a crítica sociológica privilegia nas obras a transparência do mundo real, a crítica conhecida como de estilos de época privilegia nos textos a localização das ideologias literárias de cada período. [...]" (SANT'ANNA, 1979 [1973], p. 50). O outro modelo, "a narrativa de estrutura complexa”, pode afastar-se do código vigente, permitindo conotar um significante arbitrário, definindo-se, dessa forma, como contra-ideológico.

Contudo, ainda conforme Sant'anna (1979 [1973], p. 54), se faz necessário compreender ideologia e contra-ideologia como uma variante dos mecanismos de "identidade" e "diferença", respectivamente. Ou seja, agrupar as obras segundo suas semelhanças e diferenças, confirmando a ideologia e a contra-ideologia não apenas no nível do enunciado, mas também da enunciação. A narrativa voltada para o mundo real reflete o sistema de ideias duma classe, época ou estilo em sua própria organização, e esse sistema irá guiar o comportamento de seus personagens, estabelecendo dependências miméticas com aquilo que a ideologia dominante chama de realidade. Desta forma, a narrativa de estrutura simples é transparente, produz tipos e preenche os vazios com ideologias, mistificando o indivíduo. Quando uma narrativa distancia um indivíduo de sua realidade, critica o real, rompe com a ideologia dominante e cria modos especiais de arranjo do simbólico, introduzindo "estranhamentos", não reproduzindo utopias, mas instaurando beterotopias (termo foucaultiano), temos aí uma narrativa de estrutura complexa, totalmente "opaca".

Portanto, para Sant'anna (1979 [1973], p. 54-55) a "história da literatura" seria um sistema onde a identidade e a semelhança, a transparência e a opacidade seriam igualmente importantes. Mas essa dicotomia não privilegia um valor ou outro: “[...] o sistema literário seria uma interação dialética de qualidade (diferença) e quantidade

\footnotetext{
${ }^{5}$ Escritor, ensaísta e poeta brasileiro. Foi presidente da Fundação Biblioteca Nacional nos anos 1990 e professor do curso de Pós-Graduação em Literatura Brasileira da Pontifícia Universidade Católica do Rio de Janeiro, durante a publicação de Análise estrutural de romances brasileiros.

${ }^{6}$ Crítico literário e ensaísta, foi professor da Faculdade de Filosofia, Letras e Ciências Humanas da Universidade de São Paulo.
} 
(semelhança). A diferença seria a instauração de novos paradigmas narrativos, a semelhança seria a sua continuidade sintagmática" (SANT'ANNA, 1979 [1973], p. 54-55). A proposta do autor seria então operar sua análise sob três níveis mínimos, a fim de localizar os espaços da transparência e da opacidade da narrativa: o nível da narração, dos personagens e da língua(gem).

Em relação a José de Alencar, suas obras são narrativas de estrutura simples, transparentes. $\mathrm{O}$ autor seguiu os paradigmas estrangeiros em relação à estética de que foi representante, o Romantismo: “[...] enquanto em O Guarani Alencar revalida a ideologia medieval em sua versão mítico-indianista, em Senhora afastando-se do apoio mítico ele exercita a ideologia romântico-burguesa através de uma estética idealista" (SANT'ANNA, 1979 [1973], p. 23, grifo do autor).

Quanto a isso, Candido ([196-]) concordou: “[...] toda a sua obra, por vinte anos, será renovação e enriquecimento dessas duas posições iniciais: a complication sentimentale, tenuemente esboçada em Cinco Minutos e $A$ Viuvinha, e a idealização heroica d'O Guarani" (CANDIDO, [196-], p. 221, grifo do autor). Porém, esclarece Sant'anna (1979 [1973], p. 55) que nesse jogo de sistemas, a transparência e a opacidade podem alterar-se, uma narrativa de estrutura complexa pode converter-se em simplicidade, e a narrativa de estrutura simples produzir estranhamentos e se apresentar de uma complexidade tal. É o que acontece com Alencar. O inconsciente não está apenas na "parole" da dicotomia saussuriana, mas a "langue" também pode operar inovações. Conforme o próprio Sant’anna (1979 [1973]):

[...] dentro da série literária brasileira [Alencar] é o instaurador de uma outra linguagem. Sua opacidade aparece exatamente no aspecto em que ele operou a diferença mais radicalmente, no nível da língua(gem). Aí produziu estranhamentos de ordens várias, [mesmo que] nos outros níveis - narração e personagens - não foi tão radical, tendo operado antes a adaptação de modos construídos alhures. (SANT'ANNA, 1979 [1973], p. 50 , grifo do autor).

Em termos culturais, a inovação de Alencar serviu para conduzir uma argumentação social. O encaminhamento de assuntos caros à cultura brasileira, como a antropofagia, a representação do indígena, a espacialidade geográfica brasileira foram atentamente acompanhadas pelo pensamento brasileiro, inegavelmente. $\mathrm{O}$ autor alcançou seu sucesso ao fixar-se no imaginário cultural do país, contribuindo na sua fixação e sustentação. José de Alencar é um autor nacional, digamos assim, porque o nacional é José de Alencar.

Assim é que, em Diva, Alencar representou o vestuário da elite feminina carioca com uma riqueza de detalhes nunca antes vista nas narrativas brasileiras e reivindicou, no pós-escrito, a inovação da língua portuguesa no Brasil, a fim de que suas obras se tornassem palco para a brasilidade, ambição de seu projeto nacionalista.

\section{O VESTUÁRIO DA ELITE FEMININA CARIOCA (1854-1864) EM DIVA}


O José de Alencar cronista frequentou ruas, bailes e cerimônias escrevendo um pouco sobre tudo, desde resoluções políticas, até as fofocas do dia. Deste modo, pelas suas crônicas publicadas nos jornais cariocas Correio mercantil e Diário do Rio, entre 1854 e 1855, seus leitores ficaram sabendo, por exemplo, que o espetáculo que o Teatro Lírico exibiria certa noite foi transferido, na verdade, por causa de um malestar da Charton ${ }^{7}$. E frequentaram-no já advertidos por Alencar quanto à poeira dos assentos, que sujava os vestidos das senhoras e as casacas dos cavalheiros, além de prejudicar a visibilidade do palco. $\mathrm{O}$ autor apreciava certas atitudes dos brasileiros, mas também, quando o contrário ocorria, destilava com humor sarcástico suas críticas, denunciando, por exemplo, as más condições em que se encontrava o Passeio Público, tanto por descaso do governo, quanto dos próprios leitores que, por ainda não adotarem o costume francês de passear em suas tardes livres, deixavam o local deteriorar-se.

Os salões e bailes, além do vestuário feminino eram também outra moda da França, mas que os brasileiros não demoraram nada para adotar. Nesta crônica datada de 13 de maio de 1855, publicada no Correio mercantil, descreveu Alencar ([19-]) um baile no Cassino, o salão mais popular da cidade: “[...] tocava a valsa, e a [...] fada [...] deslizava docemente, roçando [...] a terra com a ponta de um pèzinho mimoso, calçado com [...] sapatinhos de cetim branco. [...] Um [...] pèzinho que brinca sob a orla de um elegante vestido, ora escondendo-se, ora mostrando-se a furto" (ALENCAR, [19--], p. 187). O tema do pé feminino que ora se mostra, ora se esconde, será tema de todo um romance, A pata da gazela (1959 [1870]). O autor demonstra a fina compreensão do papel do romance, ao explorar um tema específico para variar sobre os gostos e comportamentos sociais. A representação do pé feminino está ligada ao fascínio da chegada dos tempos modernos, com o início da era das exposições, da imagem e do indivíduo. O século XIX nos apresenta o voyeurismo e o espanto do corpo narrado. Alencar acertava mais uma vez em suas preferências, pois desejar saber e ver sobre o corpo nunca será abandonado em nossa cultura.

Os bailes não eram somente uma forma de distração, mas também espaço para se realizarem os acordos matrimoniais. Reservados às famílias de posse, constituíam verdadeiras exibições de luxo e poder aquisitivo. Mas Alencar não poupou seus leitores dos aspectos desagradáveis do Cassino: esse jovem sisudo, com aquela barba cerrada que se tornou sua marca, deixando correr a sua pena também futricou sobre aquela "[...] escada imoral, porque deixa ver as pernas de tôdas as môças e velhas que sobem. Basta postar-se um homem no saguão durante a noite para fazer um estudo completo da pernologia da cidade" (ALENCAR, [19--], p. 211, grifo do autor). Ou então, quanto ao seu serviço, onde não havia pão, e "um baile sem pão é uma falta imperdoável, é um atentado à galanteria, uma coisa incompreensível” (ALENCAR, [19--], p. 211). Este era o cardápio servido: “às dez horas - [...] - chá. Às onze horas - [...] - sorvetes. À meia-noite - [...] - empadas [e confessa que já estava farto

\footnotetext{
${ }^{7}$ Cantora lírica muito famosa na época. (N. A.).
} 
daquelas empadas]. A uma hora - [...] - chocolate" (ALENCAR, [19--], p. 211). Esta regra foi representada em Diva: "uma noite de reunião, servia-se o chocolate. Ela ia tomar uma xícara na bandeja que passava [...]” (ALENCAR, 1959, p.478, grifo meu).

Eis então com que medida o escritor "dá foros de veracidade ao painel da leitura romântica” (LAJOLO; ZILBERMAN, 1996, p. 267), ao preencher seus romances com elementos desse cotidiano burguês que ele registrava em suas crônicas. Os vestuários das moças casadoiras eram dignas atrações para os leões ${ }^{8}$ a postos: “[...] já o baile tinha perdido a simetria da entrada, no meio da confusão que é o seu maior encanto: a música, as vozes, os risos, os ruge-ruges das sêdas, os burburinhos da festa, enchiam o salão" (ALENCAR, 1959 [1864], p. 476). Por conseguinte, um elemento que não poderia deixar de preencher a diegese de Diva. A mulher deveria valsar com seus admiradores, expor seus talentos no piano e exibir seus toilettes de baile produzidos em ricas fazendas. A moda constituía uma verdadeira atração, e a indiferença calculada da mulher chegava a ficar em segundo plano, ofuscada por uma postura elegante e por aqueles vestidinhos decotados, como se pode ver em uma crônica de $O$ espelho: revista semanal de litteratura, modas, industria e artes $(1859 a)$ :

Uma mulher elegante, sempre attrahe simpathias e muita vez torna-se amada, [...]; por que um vestido bem talhado, uma flôr no cabelo, uma luva de pellica, umas botinas de salto, [...], fazem-nos suppor um véo occultando o paraiso [...]. E quantas vezes os olhos dessa mulher não cintilam de colera, os seus pesinhos não batem com força no chão acompanhados de um aspero não quero! Mas que nos importa isso, [...]; pouco se nos dá das formas que aquellas cassas occultam : olhamos para essa mulher poeticamente, porque a elegância de tudo quanto nella se apresenta faz-nos acredital-a tambem a poetisa do toilette. (CHRONICA..., 1859a, p. 11, grifo do autor).

Alencar (1959 [1864]), ao descrever a entrada da personagem Emília no Cassino, traduz todo o encanto que o seu vestuário causava ao redor, fazendo jus ao seu título de "diva":

seu trajo era um primor do gênero, pelo mimoso e delicado. Trazia o vestido de alvas escumilhas, com a saia tôda rofada de largos folhos. Pequenos ramos de urze, com um só botão côr-de-rosa, apanhavam os fofos transparentes, que o menor sôpro fazia arfar. O fôrro de seda do corpinho, ligeiramente decotado, apenas debuxava entre a fina gaza os contornos nascentes do gárceo colo; e dentre as nuvens de rendas das mangas só escapava a parte inferior do mais lindo braço. (ALENCAR, 1959 [1864], p. 482).

A representação do vestuário da elite feminina carioca em seu perfil de mulher não passa nunca despercebida: à medida que Emília é introduzida aos espaços públicos e privados, Alencar nos dá descrições dos toilettes que usa. Seja por uma falha na narrativa, escolhendo representar o vestuário da década de 50 do século XIX (como discutido no capítulo 3), seja porque "as últimas tendências da moda

\footnotetext{
${ }^{8}$ Gíria da época para os mancebos da alta sociedade, trajados no último rigor da moda e que, para subirem na concorrência ao casamento, prostravam-se ante as moças ricas. (N. A.).
} 
parisiense chegavam à Corte com atraso" (CHRONICA, 1859b, p. 10), o figurino da estreia de Emília no Cassino ultrapassa as páginas de ficção, podendo ter satisfeito uma leitora moça nos anos 1860, que ainda poderia copiar aquele figurino de uma década atrás, como quase certamente permitiu às leitoras senhoras recordarem verdadeiro deleite - de seus próprios figurinos, quando frequentaram há dez anos os bailes, em busca de casamento, pois há correspondências entre o que leram no romance e as informações das revistas. De acordo com estas, o uso das fazendas de escumilha (tecido muito fino de seda), como a do vestido de Emília, era, por motivos de economia, regra nos bailes dos anos correspondentes ao tempo da diegese de Diva; já nos anos 1860, o uso da cassa (tecido de algodão) se tornou mais frequente, ambos nas cores prediletas das brasileiras: "[...] a branca, symbolo da inocência ; a azul que faz lembrar o cèo ; e a roséa que è um attributo do pudor" (SOUSA, 1861, p. 24). Assim, o romance, além de significar uma leitura contemporânea, também refaz um espaço da memória, principalmente nas leitoras posteriores à década do lançamento do livro. Nelas, há a reminiscência do vestuário e dos momentos festivos através do ato de leitura da narrativa. Segue um exemplo em O jornal das senhoras: moda, litteratura, bellas-artes e theatros (1855c):

Vestuario de baile [figurino da direita]. - Vestido de nobreza branca, coberto por tres saias de escomilha branca, [...]; o peitilho é todo coberto de franguinhas e o cabeção que vem até o cinto é também coberto de flores. Vestuario de baile a' sahida [figurino da esquerda]. - Vestido de seda adamascado cor de rosa. Sahida de baile de pelucia branca com listras verdes. Capucho de renda preta sobre a cabeça, muito leve para não machucar o penteado. (DESCRIPÇÃO..., 1855c, p. 84).

Outros modelos também são sugeridos:

Vestido de tafetá com bertha e triplice saia de filó : corpinho mui decotado, cintura espartilhada e de bico, [...] ; nas extremidades, no alto e em baixo, uma pequena blonde [figurino da esquerda]. Na frente e sobre cada hombro um ramo de flores variadas, [...]. Cada uma das saias de filó é reerguida por uma prisão de flores iguaes ás de cima [...], emquanto outra palma de folhagem acompanha a orla para o lado da frente. Penteado de bandós em tufos crespos, [...] e nelle entroduzidos dous ramos das mesmas flores [figurino da direita]. (DESCRIPÇÃO..., 1855d, p. 186, grifo do autor).

Diversos outros detalhes são reunidos e representados por Alencar ao longo do romance, como a importância do uso das luvas nos bailes, tendo sido representada em uma cena:

- Desculpe-me. Não posso dançar!

- Por que motivo, D. Emília?

Ela calou-se; mas fitou-lhe as mãos com olhos tão expressivos que o môço compreendeu e corou:

- Tem razão. Tirei as luvas para tomar chá e esqueci-me de calçá-las. (ALENCAR, 1959, p. 480). 
A correspondência dessa regra de uso do acessório encontra-se num artigo publicado em $O$ espelho (1859): "não há moça de mão delicada, nem rapaz do tom, que deixe de trazer a sua luva de pellica. [...] A luva [sic] pois é tão necessária para quem vai ao baile, como é preciso o lenço para quem tem defluxo" (AZEVEDO, 1859, p. 7, grifo do autor).

Outro aspecto é a descrição da saída de baile da protagonista: “[...] ela surgiu diante de nós, envôlta em sua ampla mantilha côr de cinza, que lhe ocultava todo o corpo e cingia com uma das pontas o colo e parte da cabeça [...]" (ALENCAR, 1959 [1864], p. 486), correspondente à descrição abaixo: “[...] um bornous de pelúcia branca e outro de cachemira, bordado com ligeiro fio de ouro, com o competente capuz tambem bordado e enfeitado por tres borlas de ouro" (SOUSA, 1861, p. 24, grifo do autor).

Da mesma forma são seus figurinos de passeio: “[...] uma capa de cachemira escura cobria-lhe quase todo o vestido" (ALENCAR, 1959 [1864], p. 524-525). No jornal das senhoras (1855a, 1855b) lê-se: "Vestuario de passeio. - Vestido de moire antique còr de violeta: capote de cachemira enfeitado de fita de pelucia e franja. [Figurino da esquerda]" (DESCRIPÇÃO..., 1855a, p. 10, grifo do autor). Ou ainda: "Vestido de nobreza, saia de dous folhos enfeitados de tiras de pelucia. Capote de veludo enfeitado com o mesmo enfeite. [Figurino da direita]" (DESCRIPÇÃO..., 1855b, p. 42, grifo do autor).

\section{CONSIDERAÇÕES FINAIS}

Já que para Genette (2017 [1972], p. 88) não há mais a distinção platônica entre mimésis e diegese, e esta agora passa a conter graus de mimésis, o romance é então considerado um gênero narrativo "misto", representando o dia a dia do homem burguês. Sendo este o propósito do gênero, era esperado que as obras alencarianas estivessem preenchidas com os elementos que circundaram a vida social burguesa. Já que Augusto é o narrador-autor de Diva, e G.M. quem recebe a carta de Paulo e lhe dá a moldura, a voz de Alencar não invade em nenhum momento a narrativa. Sabemos que ele é seu autor real, porém incorpóreo - é possível considerar então G.M. uma hipóstase de Alencar? Sua ausência na narrativa é o cúmulo da objetividade, necessária para ser representada nos romances a realidade.

A descrição, que abandona o curso da história por meio de uma pausa na narrativa - essa “"entrada' é evidentemente só do narrador e do leitor [...]" (GENETTE, 2017 [1972], p. 168), cuja função é familiarizar este com a diegese -, permitiu relacionar esta com a metadiegese, conferindo o verossímil ao vestuário representado no romance. Após estabelecer as comparações, observamos que Alencar poderia ter elaborado um vestuário em nada condizente à realidade das mulheres de elite. Contudo, se ele reproduziu a ideologia romântico-burguesa na diegese, nada mais óbvio do que transpor e informar, ao descrever em Diva com detalhes minuciosos, aqueles mesmos vestidos que presenciava nos bailes e nas revistas femininas. Isto é, os graus de distância que a sua informação narrativa 
manteve com as características do vestuário de 1854-1864 foram os mais próximos da realidade (segundo o ponto de vista da ideologia burguesa), com o máximo de detalhes, e da forma mais direta possível. Deste modo, Alencar representou o vestuário da elite feminina carioca na diegese do romance, aproximando a leitora da instância narrativa. Por se situar num nível de existência fora da diegese, ou na metadiegese, foi possível conferir, portanto, ao vestuário da elite feminina carioca na narrativa de Diva o estatuto daquilo que Genette (2017 [1972], p. 342) toma por metadiegético. Em Diva, o elemento vestuário "só pode visar um narratário [leitor] extradiegético que se confunde aqui com o leitor virtual, e com o qual cada leitor real pode se identificar" (GENETTE, 2017 [1972], p. 342). A partir disso, José de Alencar, ao preencher as páginas de seu perfil de mulher com a vida social da cidade do Rio de Janeiro do século XIX pressupôs uma leitora real que tivesse conhecimento das informações ali contidas, sendo possível identificar verossimilhança nas descrições dos toilettes - tornando, portanto, a mensagem do autor compreensível - e desfrutar de uma leitura agradável e prazerosa.

Se, de acordo com Sant'anna (1979 [1973] p. 42), o êxito de uma narrativa depende do quanto melhor reproduza o "sistema de atitudes" e o "sistema de ideias", nesta situação, da ideologia romântico-burguesa, esta transparecendo " [...] no desempenho dos personagens que atuam semelhantemente a indivíduos do espaço real” (SANT"ANNA, 1979 [1973], p. 42), e Alencar reprisa “[...] na ficção cenas já encontradas no memorialismo, fato sugestivo de que [sua ficção] [...] incorporava um flagrante do cotidiano brasileiro do século XIX [...]" (LAJOLO; ZILBERMAN, 1996, p. 268), como demonstrado nesta pesquisa, então só nos resta concluir que o autor obteve êxito em seu trabalho, ao representar com um grau bastante próximo a realidade, segundo o ponto de vista da ideologia burguesa, como o representante exemplar que foi do movimento literário de que fez parte, o Romantismo. Envolvido nos assuntos de seu tempo, acertou sobre os temas que escolheu escrever, garantindo às suas obras uma possível recepção por parte de seu público-alvo, seja através de leitoras fictícias que elaborou para garantir tal aceitação, seja na representação da vida privada do homem comum.

Representar em Diva aspectos como o vestuário significava oferecer uma distração certa, visto que Alencar sabia que a sociedade brasileira era "[...] uma sociedade que se ocupava de outras atividades, quiçá com maior poder de distração que a leitura, e o 'dinamismo' em que se encontrava envolta não suportaria leituras mais densas” (SILVA, 2011, p. 78-79, grifo da autora). Ele decorreu sobre temas de interesse certo para um perfil de leitores que conhecia muito bem, permitindo-lhe, desta forma, por meio de sua escrita, orientá-los no desenvolvimento de sua identidade nacional, ao terem acesso a uma literatura essencialmente brasileira.

\section{REFERÊNCIAS}

ALENCAR, José de. Ao correr da pena: crônicas publicadas no "Correio Mercantil", de 3 de setembro de 1854 a 8 de julho de 1855, e no "Diário do Rio", de 7 de outubro 
de 1855 a 23 de novembro do mesmo ano, ambos os jornais do Rio de Janeiro. São Paulo: Instituto de Divulgação Cultural, [19--].

ALENCAR, José de. 1959 [1864]. Diva. In: José de Alencar obra completa. Rio de Janeiro: José Aguilar. p. 459-570. v. 1.

ALENCAR, José de. 1959 [1862]. Lucíola. In: Rio de Janeiro: José Aguilar. p. 307-458. v. 1.

ALENCAR, José de. 1959 [1870]. A pata da gazela. In: Rio de Janeiro: José Aguilar. p. 571-687. v. 1.

ALENCAR, José de. 1959 [1875]. Senhora. In: . Rio de Janeiro: José Aguilar. p. 941-1214. v. 1.

AZEVEDO, M. de. As luvas. O espelho: revista semanal de litteratura, modas, industria e artes, Rio de Janeiro, n. 1, p. 7, 4 set. 1859. Disponível em: http: $</ /$ bndigital.bn.gov.br/hemeroteca-digital/>. Acesso em: 23 set. 2018.

CANDIDO, Antonio. O triunfo do romance. In: Formação da literatura brasileira: momentos decisivos. 3. ed. São Paulo: Martins, [196-]. p. 221-235. v. 2.

CHRONICA elegante. O espelho: revista semanal de litteratura, modas, industria e artes, Rio de Janeiro, n. 1, p. 11, 4 set. 1859a. Disponível em: http: <//bndigital.bn.gov.br/hemeroteca-digital/>. Acesso em: 23 set. 2018.

CHRONICA elegante. Rio de Janeiro, n. 2, p. 10, 11 set. 1859b. Disponível em: http:<//bndigital.bn.gov.br/hemeroteca-digital/>. Acesso em: 23 set. 2018.

CONCEIÇÃO, Fernanda de Oliveira; ARAÚJO, Andréia Silva de. Aurélia Camargo sob as tramas do amor cortês: uma relação entre Senhora e o código do amor medieval. Anais do VIII Seminário de Estudos Filológicos: Filologia e Humanidades Digitais, Feira de Santana, p. 367-373, 2016. Disponível em: $<$ https://seminariodeestudosfilologicos.com/anais-do-viii-seminario-de-estudosfilologicos/>. Acesso em: 07 nov. 2018.

DESCRIPÇÃO da estampa. Jornal das senhoras: moda, litteratura, bellas-artes e theatros, Rio de Janeiro, n. 2, p. 10, 14 jan. 1855a. Disponível em: http:<//bndigital.bn.gov.br/hemeroteca-digital/>. Acesso em: 26 set. 2018.

Rio de Janeiro, n. 6, p. 42, 11 fev. 1855b. Disponível em: http: <//bndigital.bn.gov.br/hemeroteca-digital/>. Acesso em: 26 set. 2018.

, Rio de Janeiro, n. 11, p. 84, 18 mar. 1855c. Disponível em:

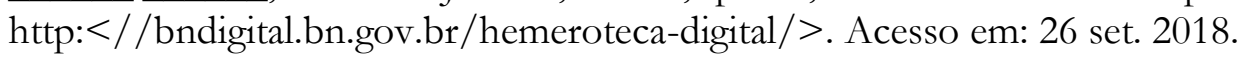

Rio de Janeiro, n. 24, p. 186, 17 jun. 1855d. Disponível em:

http: <//bndigital.bn.gov.br/hemeroteca-digital/>. Acesso em: 26 set. 2018.

FILHO, Luís Viana. A vida de José de Alencar. Rio de Janeiro: J. Olympio; Brasília: INL, 1979.

GENETTE, Gérard. 2017 [1972]. Figuras III. 1. ed. Tradução de Ana Alencar. São Paulo: Estação Liberdade.

LAJOLO, Marisa; ZILBERMAN, Regina. A formação da leitura no Brasil. São Paulo: Editora Ática, 1996.

MENDES, Oscar. José de Alencar: romances urbanos. Rio de Janeiro: Editora Agir, 1965. 
PINHO, Adeítalo Manoel. O sistema literário de "A conquista": nomes, leitura e números para um romance de Coelho Neto. Literatura em debate, Rio Grande do Sul, v. 3, n. 4, p. 109-128, ago. 2009. Disponível em: http: $</ /$ revistas.fw.uri.br/index.php/literaturaemdebate/article/view/468/849>. Acesso em: 14 abr. 2019.

PINHO, Wanderley de Araújo. O salão de Nabuco: um namoro de José de Alencar. In: Salões e damas do segundo reinado. 2. ed. São Paulo: Martins, [19--?]. p. 155-165.

REIS, Adriana Dantas. Cora: lições de comportamento feminino na Bahia do século XIX. Salvador: FCJA, Centro de Estudos Baianos da UFBA, 2000.

SANT'ANNA, Affonso Romano de. 1979 [1973]. Análise estrutural de romances brasileiros. 5. ed. [S. l.]: Petrópolis: Vozes.

SILVA, Edinage Maria Carneiro da. Progresso e modernização: o projeto de José de Alencar para as letras do Brasil. In: ARAÚJO, Maria da Conceição Pinheiro; NOGUEIRA, Juliana Gomes; PINHO, Adeítalo Manoel. (Org.). Literatura, bistória e memória: leituras de Jacques Le Goff. Feira de Santana: UEFS Editora, 2011. p. 73-82. SOUSA, E. de. Chronica elegante. A primavera: revista semanal de litteratura, modas, industria e artes, Rio de Janeiro, v. 1, n. 2, 3 mar. 1861. Disponível em: http:<//bndigital.bn.gov.br/hemeroteca-digital/>. Acesso em: 23 set. 2018.

WATT, Ian. $A$ ascensão do romance: estudos sobre Defoe, Richardson e Fielding. Tradução de Hildegard Feist. São Paulo: Companhia das Letras, 1990. 